\section{Condicionantes da amamentação exclusiva na perspectiva materna}

\section{Conditioning factors for exclusive breastfeeding from the mother's perspective}

\section{Condicionantes de la lactancia exclusiva desde la perspectiva materna}

Gabriele Pereira Rocha 1

Maria do Carmo Fontes Oliveira 1

Luciana Beatriz Bastos Ávila 2

Giana Zarbato Longo 1

Rosângela Minardi Mitre Cotta 1

Raquel Maria Amaral Araújo 1

\section{Resumo}

O objetivo do estudo foi explorar, entre nutrizes, as vivências positivas e negativas na realização da prática da amamentação exclusiva. Foi realizado um estudo descritivo, qualitativo, envolvendo 18 nutrizes com filhos de até um ano de idade, recrutadas no Serviço de Imunização do Município de Viçosa, Minas Gerais, Brasil. Os dados foram obtidos por meio de entrevistas gravadas e transcritas. O corpus foi submetido à análise de conteúdo para averiguação das unidades temáticas relacionadas às vivências positivas e negativas, e, em seguida, foram construídos dois textos correspondentes a cada situação. Esses textos foram submetidos à análise de similitude com o auxílio do software IRAMUTEQ, gerando duas árvores de similitude. A interpretação das árvores de similitude foi realizada a partir das linhas de concordância produzidas pelo software AntConc. As principais vivências negativas na amamentação exclusiva foram a demanda constante da criança pelo peito, a impossibilidade de distanciar-se da criança, a dor ao amamentar e a insegurança quanto à capacidade de produzir leite suficiente. As principais vivências positivas foram os benefícios biológicos do leite materno, o vínculo mãe-filho, a praticidade e o menor custo. O estudo possibilitou a apreensão das dimensões positivas e negativas ligadas à amamentação exclusiva e sugere a importância da assistência profissional à mulher na fase inicial da amamentação e do apoio da rede social para amenizar a sensação de sobrecarga da mulher.

Aleitamento Materno; Desmame; Lactente; Mães

\author{
Correspondência \\ G. P. Rocha \\ Universidade Federal de Viçosa. \\ Edificio Centro de Ciências Biológicas II, Campus Universitário, \\ Viçosa, MG 36570-900, Brasil. \\ gabrielerochap@gmail.com \\ 1 Universidade Federal de Viçosa, Viçosa, Brasil. \\ 2 Instituto de Humanidades, Artes e Ciências, Universidade \\ Federal do Sul da Bahia, Porto Seguro, Brasil.
}




\section{Introdução}

Na atualidade, muito se sabe a respeito da importância da amamentação para a saúde da criança e de sua mãe, a curto e em longo prazo ${ }^{1}$. Grande parte desses benefícios são potencializados quando a amamentação ocorre de forma exclusiva 2.

O Brasil tem registrado avanços na prática da amamentação, porém a oferta precoce de outros alimentos à criança é uma realidade preocupante 3 , uma vez que isso impede a criança de usufruir dos benefícios da oferta exclusiva do leite materno até completar seis meses de idade, além de favorecer o risco de morbidades 1,2 .

Parece, no entanto, que essa dificuldade de as mulheres realizarem a amamentação exclusiva está também presente em outros países. Dados de 127 países de baixa e média renda e de 37 países de alta renda revelam que, em quase todos esses países, a oferta de leite materno aos recém-nascidos fica acima de $80 \%$, porém, na sua maioria, a oferta exclusiva de leite materno é bem abaixo de $50 \% 1$.

Os fatores que influenciam a amamentação, e consequentemente sua modalidade exclusiva, são multidimensionais, envolvendo questões sociais, econômicas, culturais e psicológicas ${ }^{4}$. Revisão sistemática de estudos epidemiológicos conduzidos no Brasil encontrou 36 fatores associados à amamentação exclusiva 5. Os fatores mais frequentemente associados foram o local de residência, ora urbana ora rural, idade materna intermediária, escolaridade materna crescente, ausência de trabalho materno, idade da criança decrescente, não uso de chupeta e financiamento privado da atenção primária à saúde 5 .

Os estudos desenvolvidos com abordagem da pesquisa qualitativa têm contribuído para a elucidação dos elementos envolvidos no processo da amamentação e demonstram que, na visão das mães, essa prática é carregada de aspectos positivos e negativos 6 . Os aspectos negativos abordados incluem o cansaço, a limitação do seu tempo para exercer as funções de mãe-mulher e de trabalhadora e a necessidade de ajuda para realizar a amamentação ${ }^{6}$. Polido et al. 7 , por meio de um estudo etnográfico com primíparas e familiares, buscaram identificar aspectos relevantes para a ocorrência da amamentação exclusiva mais prolongada. Nesse estudo, verificaram que a motivação das mães favoreceu o prolongamento dessa prática, assim como o conhecimento sobre os seus benefícios e o apoio da família.

No âmbito da promoção da saúde infantil e materna, tendo, em conta, as evidências sobre os benefícios da amamentação exclusiva e a demanda por estudos que favoreçam a elevação de suas taxas, cabe ainda investigar quais condicionantes são mais significativos para a mulher, haja vista ela avaliar riscos e benefícios na tomada de decisões sobre a amamentação ${ }^{8}$. Conhecer a percepção da nutriz sobre o que considera mais relevante dentre os aspectos positivos e negativos da amamentação exclusiva pode favorecer o direcionamento das estratégias de apoio à nutriz.

Silva 8 desenvolveu o modelo teórico "Pesando Riscos e Benefícios", no qual demonstra que a mulher atribui significados às vivências da amamentação, os quais influenciam sua tomada de decisões. Ela percebe sentimentos relativos à prática de amamentar como fatores que refletem na vida do recém-nascido, na dela própria ou no conjunto familiar e, ao tomar decisões sobre a amamentação, pesa os riscos e os benefícios. Os riscos são a possibilidade de perda, prejuízo, dano, desvantagem, perigo e ameaça física ou emocional para mãe e filho, ou uma de suas partes, e os benefícios se referem a ganhos, proveitos e vantagens obtidos pela amamentação, por ela ou pela criança, ou ambas 8 .

Baseando-se nesse modelo, pressupõe-se que a mulher, ao ponderar riscos e benefícios da amamentação exclusiva, coloca, em evidência, os condicionantes que ela considera mais significativos. Diante do exposto, o presente estudo objetivou explorar, entre nutrizes, as vivências positivas e negativas na realização da amamentação exclusiva, buscando identificar os condicionantes mais relevantes a partir da perspectiva materna.

\section{Metodologia}

Foi realizado um estudo descritivo com abordagem qualitativa que envolveu 18 nutrizes. Essas mulheres foram recrutadas pela pesquisadora por ocasião da realização da vacinação do filho no Serviço de Imunização do Município de Viçosa, Minas Gerais, Brasil, durante os meses de maio a julho 
de 2015. A amostragem foi por conveniência, ou seja, incluiu todas as mulheres que compareceram ao serviço no período de estudo e que eram nutrizes com filhos de 6 a 12 meses de idade, além de aceitarem participar da pesquisa. A amostra foi definida pela saturação, que é alcançada quando as informações obtidas começam a apresentar certa redundância ou repetição 9 .

O processo interpretativo se baseou no modelo teórico "Pesando Riscos e Benefícios", compreendendo que a mulher vivencia a amamentação a partir de um processo avaliativo e valorativo, e toma decisões sobre a amamentação pesando os riscos e os benefícios desse ato ${ }^{8}$. Assim, foram realizadas entrevistas abertas gravadas em aparelho de áudio portátil e conduzidas de modo que as nutrizes expressassem suas vivências positivas e negativas da amamentação exclusiva até os seis meses de idade da criança. Para isso, as entrevistas foram conduzidas a partir da seguinte pergunta norteadora: "Amamentar é algo fácil ou difícil? Fale-me o que você considera como dificuldades/desestímulos e/ ou facilidades/estímulos para realizar a amamentação exclusiva?”. Buscou-se promover um ambiente favorável ao diálogo, de modo a permitir à mulher sentir-se confortável, com liberdade e confiança para expor suas vivências e percepções do processo de amamentação. As entrevistas duraram, em média, 30 minutos, e todas foram realizadas pela pesquisadora. As transcrições ocorreram no mesmo dia das entrevistas para evitar possíveis perdas de áudio e permitir a anotação da captação de memórias em relação às expressões de cada participante, tom de voz ou outras observações que pudessem ajudar na interpretação dos relatos posteriormente.

O significado do termo amamentação exclusiva foi explorado com as nutrizes no sentido de garantir a compreensão por parte delas sobre o seu conceito, qual seja, oferta de leite materno e de nenhum outro alimento líquido ou sólido, e oferta apenas de medicamentos na forma de gotas, xaropes (vitaminas, minerais) e soro (solução glicosada e outros diluentes) 10.

O corpus foi submetido, inicialmente, à análise de conteúdo para verificação das frequências referentes às vivências positivas e negativas presentes nos depoimentos, e, a partir daí, foram construídos dois textos, um representativo das vivências positivas e outro representativo das vivências negativas da amamentação exclusiva. O processo de construção dessas categorias se baseou na literatura científica sobre amamentação e seus fatores condicionantes.

Esses textos foram submetidos à análise de similitude, que permite a visualização da conexidade entre as palavras e identifica as palavras com maior frequência e coocorrência no corpus, denominadas itens lexicais centrais, e também as palavras próximas a esses, denominadas itens lexicais periféricos. Essa análise favorece a apreensão dos principais núcleos de sentidos do corpus.

A análise de similitude foi realizada com auxílio do software IRAMUTEQ (Interface de R pour les Analyses Multidimensionnelles de Textes et de Questionnaires; http://iramuteq.org) que se baseia na teoria dos grafos. Essa análise é processada por meio de indicadores estatísticos que apresentam uma árvore de palavras com ramificações fundamentadas nas relações que uma possui com a outra, que auxilia na visualização da conexidade entre as palavras.

Utilizamos a árvore de similitude para compreender a organização da estrutura dos relatos, identificar o agrupamento de um conjunto de palavras e a força das conexões desse conjunto de palavras no corpus.

A análise da árvore de similitude foi realizada por meio da consulta direta ao corpus. Foram isolados todos os agrupamentos, ou seja, cada item lexical central e seu sistema periférico, e, após isso, foi realizada a busca no corpus de todos os itens lexicais centrais e suas palavras periféricas para selecionar todos os segmentos da mensagem condizentes a esses termos e realizar a interpretação dos núcleos de sentidos.

A busca dos itens lexicais foi realizada por meio do software AntConc, versão 3.2.4 (http://www. laurenceanthony.net/software/antconc/), que possibilita realizar a análise de concordância, o qual gera linhas de concordâncias no texto com o termo que se deseja revelar.

Este estudo foi desenvolvido de acordo com os aspectos éticos de pesquisas com seres humanos definidos pela Resolução no 466/2012, do Conselho Nacional de Saúde. A pesquisa foi aprovada pelo Comitê de Ética em Pesquisa com Seres Humanos da Universidade Federal de Viçosa (sob o parecer no 1.448.817). Todas as participantes receberam esclarecimentos sobre as finalidades e objetivos do estudo e assinaram o Termo de Consentimento Livre e Esclarecido. 


\section{Resultados}

As participantes eram moradoras urbanas, com escolaridade acima de cinco anos e, em sua maioria, trabalhadoras fora do lar (73\%), com renda per capita inferior a um salário mínimo (72\%), primíparas (56\%) e conviviam com o companheiro (89\%). A mediana de idade foi de 30,5 anos (mínimo 17 anos e máximo 39 anos) (Tabela 1).

A maioria $(66,7 \%)$ das participantes considerou a prática da amamentação exclusiva difícil e foi possível, por meio da árvore de similitude, identificar os elementos mais importantes das falas sobre as vivências positivas e negativas da amamentação exclusiva com base na frequência e na associação entre as palavras (Figuras 1 e 2).

\section{Tabela 1}

Características socioeconômicas das nutrizes. Viçosa, Minas Gerais, Brasil.

\begin{tabular}{|c|c|c|}
\hline Variáveis & $\mathbf{n}$ & $\%$ \\
\hline \multicolumn{3}{|l|}{ Idade (anos) } \\
\hline$<20$ & 3 & 17 \\
\hline $20-35$ & 9 & 50 \\
\hline$\geq 35$ & 6 & 33 \\
\hline \multicolumn{3}{|l|}{ Escolaridade (anos) } \\
\hline $5-8$ & 5 & 28 \\
\hline $9-12$ & 5 & 28 \\
\hline$\geq 13$ & 8 & 44 \\
\hline \multicolumn{3}{|c|}{ Renda per capita (salários mínimos *) } \\
\hline$<1$ & 13 & 72 \\
\hline $1-2$ & 5 & 28 \\
\hline \multicolumn{3}{|l|}{ Local de moradia } \\
\hline Urbano & 18 & 100 \\
\hline \multicolumn{3}{|l|}{ Estado civil } \\
\hline Solteira & 2 & 11 \\
\hline Casada & 12 & 67 \\
\hline Amasiada & 4 & 22 \\
\hline \multicolumn{3}{|l|}{ Trabalho materno } \\
\hline Dona de casa & 2 & 11 \\
\hline Doméstica & 2 & 11 \\
\hline Vendedora & 2 & 11 \\
\hline Operadora de caixa & 2 & 11 \\
\hline Cabeleireira & 2 & 11 \\
\hline Pedagoga & 1 & 6 \\
\hline Professora & 2 & 11 \\
\hline Enfermeira & 1 & 6 \\
\hline Médica veterinária & 1 & 6 \\
\hline Estudante & 3 & 16 \\
\hline \multicolumn{3}{|l|}{ Paridade } \\
\hline Primípara & 10 & 56 \\
\hline Multípara & 8 & 44 \\
\hline \multicolumn{3}{|l|}{ Amamentou } \\
\hline $\operatorname{Sim}$ & 18 & 100 \\
\hline \multicolumn{3}{|c|}{ Aleitamento materno exclusivo (meses) } \\
\hline$<6$ & 15 & 83 \\
\hline$\geq 6$ & 3 & 17 \\
\hline
\end{tabular}

* $\mathrm{R} \$ 937,00$. 
Figura 1

Árvore de similitude das vivências negativas na amamentação exclusiva. Viçosa, Minas Gerais, Brasil.

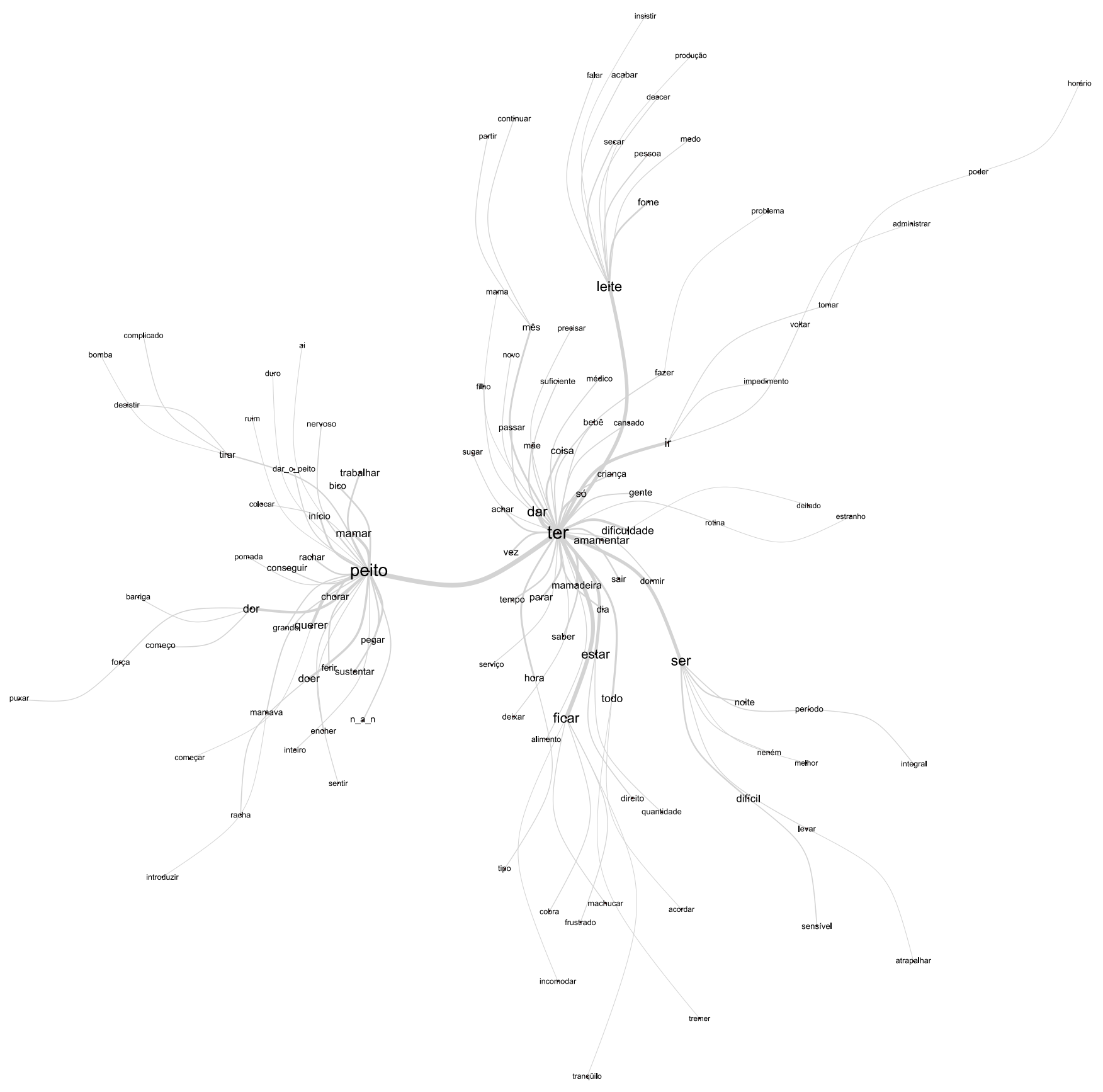

A partir da análise de similitude, verificamos que os sentidos atribuídos às vivências negativas da amamentação exclusiva foram semelhantes para todas as nutrizes. Dessa forma, considera-se, neste estudo, que a fala de uma nutriz representa a fala de todas, mesmo havendo, no grupo, diferenças quanto aos condicionantes socioeconômicos e obstétricos mais frequentemente associados à prática 
Figura 2

Árvore de similitude das vivências positivas na amamentação exclusiva. Viçosa, Minas Gerais, Brasil.

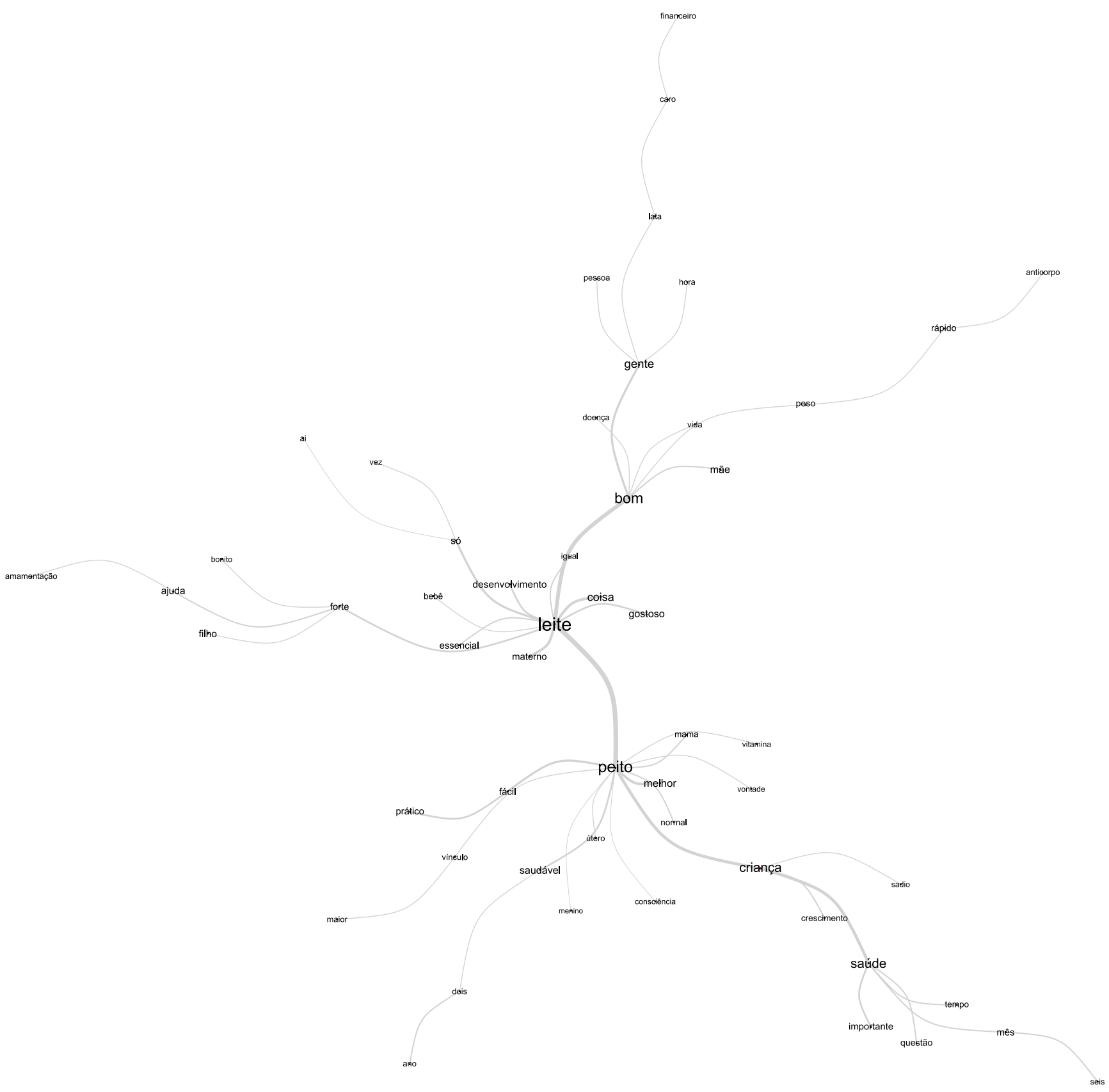

da amamentação, a saber: idade; escolaridade; trabalho fora do lar; presença de um companheiro e paridade.

Em relação às vivências negativas, os elementos lexicais centrais foram: ter, peito, ser, leite, ficar, dar, estar e ir (Figura 1).

A partir da verificação da conexidade das palavras e da análise dos contextos em que essas apareciam nos depoimentos, foi possível identificar, nas falas referentes às vivências negativas, os sentidos 
de necessidade/obrigação (tem que/ter que) de atender a demanda da criança. Essa demanda da amamentação exclusiva exige que a mãe esteja disponível para alimentar o filho e pode gerar, na nutriz, o ônus ou "peso" dessa obrigação devido à rotina comprometida.

A obrigação se relaciona ao sentido de impossibilidade de distanciar-se da criança para realizar outras atividades como cuidar de si, realizar atividades de lazer (passear), distrair-se e retornar ao trabalho. Assim, a impossibilidade de conciliar a amamentação exclusiva com essas outras atividades pode tornar necessária a introdução de alimentos alternativos ao leite materno nos períodos em que a mãe necessita estar longe do filho.

“...Você querer ir para rua olhar, passear, ver uma coisa diferente, sair daquele ambiente só ali do bebê, as preocupações com alimentação, de dar banho, de tudo que envolve, então, tem hora que você tem que espairecer" (Mãe 9).

“...No começo, foi essa coisa de três em três horas tinha que dar mamar, então aquela coisa, mamou tal hora dali três horas dar de novo, eu tinha que parar e, como ela sugava menos, com menos força, ela ficava uma hora, uma hora e quinze, e eu sou muito ansiosa (...) incomodava quando eu amamentei minha primeira filha nos primeiros meses, ficar parando toda hora, toda hora, se fosse só duas vezes no dia, acho que seria melhor, mas tinha que dar e à noite também tinha que dar então isso eu achei meio estranho, toda hora eu tenho que ficar parando...” (Mãe 11).

"Não tem como levar para mim no serviço sabe, porque não é tão pertinho e, para ela, sair e voltar de casa toda hora fica ruim sabe, tem esse impedimento que ela vai ter que administrar outro tipo de comida nesse período sabe. (...) Eu não voltei a trabalhar ainda, eu estou adiando...." (Mãe 6).

A amamentação exclusiva foi relatada como uma prática que exige da mãe possuir tempo (ter). A mãe deve priorizar seu tempo para a realização da amamentação exclusiva em detrimento às outras atividades diárias que a mulher-mãe desempenha no seu dia a dia. Uma prática cansativa e desgastante que exige paciência e disposição da mãe que vivencia uma rotina intensa.

"...A gente tem que ter tempo, disponibilizar tempo pra criança para deixar eles mamar o suficiente, entendeu, tem hora que eu paro tudo que eu estou fazendo eu vou ter o tempo com ela para ela amamentar" (Mãe 7).

“...A gente mesmo se discrimina quando a gente pensa, eu não posso pensar assim que eu estou cansada, que eu queria ter um tempo para mim, que eu quero ficar tranquila, às vezes, sem ter aquela preocupação que a gente fica em excesso com o bebê..." (Mãe 11).

$\mathrm{Na}$ análise dos elementos lexicais "peito", "ser" e "ficar", evidenciou-se o tema dor. Foi comum a evocação das palavras "começo", "início" e "começar", indicando assim a dor no peito causada por transtornos na mama e episódios de ingurgitamento, principalmente nos primeiros dias da amamentação. Ao mesmo tempo, afloram, nesses relatos, as dificuldades com o manejo da amamentação, tais como a posição da pega correta e a insegurança das mães em relação à capacidade de amamentar quando, por exemplo, o choro do bebê é interpretado por elas como um sinal de que o leite materno não está sendo suficiente para alimentar o filho ou quando a criança "recusa" o peito.

“...Difícil era no começo porque dói muito, fica muito sensível, porque a criança puxa com muita força, mas difícil mesmo foi no começo. O peito fica muito cheio, a gente não está acostumada com o peito muito grande e tinha hora que eu ia com o peito na boca dele e pensava em tirar porque estava doendo muito, e ele puxava com muita força, ia com o peito e tirava de novo, depois eu tomava coragem e dava a ele. Eu tinha muito leite" (Mãe 4).

"Como estava machucado, eu ficava chorando com medo, eu não queria colocar [para amamentar]..." (Mãe 5).

“...Eu tentei, só que ele [filho] já tinha dificuldade e tava empedrando, porque tinha muito leite, ele não conseguia também pegar, só que ele pegava e era muito pouco" (Mãe 3).

Nos contextos correspondentes ao "peito", também houve relato da dor relacionada ao sentido do desejo de amamentar. Quando as mães estão enfrentando a dor causada pelos transtornos mamários, elas manifestam o desejo de não amamentar, mas, ao mesmo tempo, valorizam a oferta do leite materno por ser esse o melhor alimento para o seu filho. Quando essa ambiguidade de sentimentos culminou com desmame, foi expressa a percepção de fracasso.

“...Meu peito rachou todo, doía demais, até chorava, ela chegou até a mamar sangue de tanto que rachou. (...) Como estava machucado, eu ficava chorando com medo, eu não queria colocar. Quando ela parou de mamar, quando ela começou já a rejeitar, eu já comecei a ficar meio nervosa que ela não queria o peito" (Mãe 5). 
A obrigação também esteve relacionada ao sentido de a nutriz valorizar positivamente a amamentação exclusiva e obrigar-se a suportar o incômodo causado pelos transtornos da mama para obter sucesso nesse ato. $\mathrm{Na}$ análise do contexto, foi possível identificar sentimentos de medo e perseverança.

"No começo da amamentação, dói muito mesmo, tem que fazer o máximo o bebê pegar a aréola do peito, porque senão vai rachar, vai doer e ela não vai dar não! É uma dor no começo muito grande e muito ruim, mas pra suportar porque é muito importante" (Mãe 12).

“...Dor, no início dá muita dor, porque, quando começa, teve uma época que doeu muito, mas como as mães fazem, você segura a dor e dá o peito, tem que dá” (Mãe 16).

O item lexical "ser" assinala que a prática da amamentação exclusiva é um período difícil para elas.

“...Tem mães que amamentam a noite inteira, e eu acho que deve ser muito desgastante, não dormir uma hora”; “...Você fica muito cansada, as preocupações, uma confusão toda, a adaptação, não consegue dormir" (Mãe 9).

“...É difícil período integral continuar amamentando e é duro porque, às vezes, a mãe volta a trabalhar com quatro meses..." (Mãe 11).

Foi possível perceber, a partir do item lexical "ficar", que, como a amamentação exclusiva é considerada importante para as mães, o seu insucesso suscita sentimento de culpa e frustração devido à autocobrança. Por outro lado, a introdução de outros alimentos na dieta da criança pode representar alívio ou solução para os dilemas experimentados por elas, dentre os quais, os relacionados à percepção da quantidade insuficiente de leite.

"Só que depois eu insistir e depois ela não queria mamar no peito e eu percebi que não estava saindo quantidade suficiente $e$ comecei a dar o [fórmula infantil], eu queria que ela mamasse mais no peito, eu fiquei frustrada, mas pra não ficar mais frustrada, porque a gente já se cobra muito eu tentei aceitar a situação" (Mãe 9).

No item lexical "leite", os relatos abordam as percepções da mulher em relação ao leite produzido por elas, como leite fraco, pouco leite.

“...Eu insistia, mas tinha pouco leite, você via que passava dez minutos e ela ainda tava com fome. Eu tinha que deixar passar algumas horas mesmo pra vê se aumentava a quantidade pra ir amamentar ela, só que, nesse intervalo, ela já tava com fome...” (Mãe 9).

"A maior dificuldade é se por um acaso ela [a mãe] vê que o leite está pouco, ou alguém falar que o leite é fraco, que a criança está com fome, está chorando muito” (Mãe 11).

Em relação às vivências positivas da amamentação exclusiva, conforme apresentado nas árvores de similitude, os itens lexicais centrais foram: leite, peito, bom, gente, criança e saúde (Figura 2). Na análise das vivências positivas da amamentação exclusiva, assim como ocorreu para as vivências negativas, foi possível verificar, a partir da análise de similitude, que os sentidos atribuídos às experiências vivenciadas foram semelhantes para todas as nutrizes. Dessa forma, considera-se, neste estudo, que a fala de uma nutriz representa a fala de todas, mesmo havendo, no grupo, diferenças quanto aos condicionantes socioeconômicos e obstétricos mais frequentemente associados à prática da amamentação, a saber: idade; escolaridade; trabalho fora do lar; presença de um companheiro e paridade.

Os itens lexicais centrais "peito" e "leite" possuem conceitos que normalmente se confundem no corpus quando estão relacionados com seus qualificadores, ou seja, é comum as mães evocarem que o "leite de peito" ou "peito" ou "leite" é saudável, é bom, essencial etc., assim "leite de peito" ou "leite" ou "peito" representa para elas leite materno. Nessa perspectiva, o item lexical "leite" e "peito" e suas conexões tratam das qualidades do leite materno.

As qualidades do leite materno estão relacionadas a benefícios para a saúde da criança a citar: ser saudável, prevenir doenças, ser nutricionalmente completo, promover crescimento e desenvolvimento e ser gostoso. Por meio dos itens lexicais centrais "criança" e "saúde", foi possível apreender que, para as mães, é importante visualizar o crescimento do filho interpretado como o sinal que comprova as qualidades do leite materno.

"E eu acho que o leite do meu peito pra ele está sendo muito bom, então ele está desenvolvendo, ele mama com aquela vontade, você vê que está satisfazendo, por mais que dê mamadeira pra ele, mamadeira é gostosa, mas não é tão gostoso igual ao leite de peito, não têm tanta vitamina igual ao leite de peito, então assim, nossa previne de tanta coisa [doenças]. (...) o leite de peito é bom, isso também foi uma motivação para eu continuar dando o peito, porque eles mandaram porque é bom pra criança, a criança se desenvolve, fica uma criança saudável, previne um monte de doença..." (Mãe 4). 
"É muito bom pra criança, para o desenvolvimento né, porque o leite materno não existe igual ao leite materno, então é bom para o desenvolvimento também, então eu acho assim, quem tem oportunidade de dar, eu acho que vale a pena. Se a mãe quer um bebê saudável, um bebê com uma inteligência boa também, porque no futuro né, os primeiros dois anos é essencial ter uma alimentação boa né, eu acho que a mãe deveria mesmo dar o peito" (Mãe 5).

"É melhor para saúde dela. (...) a criança crescia mais, ajudava no crescimento dela e tudo" (Mãe 6).

Os itens lexicais "leite" e "peito" também aparecem nas falas representando o ato de amamentar exclusivamente como algo fácil, prático e que não envolve custos financeiros diretos.

"Fácil, é muito fácil. Porque está quentinho, é prático, não precisa ficar levando mamadeira, vendo a temperatura do leite, sabendo quanto tempo depois de feita eu posso dar né, então o peito é muito mais prático, se eu saio com meu bebê, se eu vou pra algum lugar que demore um pouco mais não precisa 'ai eu fiz esse leite faz tempo, não posso dar essa mamadeira', não tem que procurar um lugar que tem ou levar água aquecida, o peito é natural, é mais fácil e é melhor" (Mãe 11).

"Fácil, porque além de não ter custo financeiro (...). Até a questão financeira mesmo, porque leite de bebê não é barato, você acostumar a dar uma lata de leite de quarenta, cinquenta, uma lata por semana, financeiramente, fica muito caro, e o bebê mama muito, uma lata, às vezes, não dá uma semana, e o leite materno está aqui na gente, é só questão de querer dar. Já sai quentinho, já sai no jeito" (Mãe 16).

Além disso, os itens lexicais "leite" e "peito" e a coocorrência com as palavras "gostoso" e "vínculo" revelam que a mãe percebe o vínculo com seu filho por meio do contato durante as mamadas, dos olhares do filho e a busca pelo seio materno que são sensações que fortalecem a autoconfiança enquanto nutriz e mãe.

"...Quando tô dando o peito pra ele é quando ele olha no meu olho. Eu tô dando de mamar para ele aí ele fica brincando com a mão, pegando no meu nariz, pegando na minha boca, aí tem hora que ele para e fica olhando dentro do meu olho, é tão gostoso, é tão satisfatório ver ele mamando e olhando pra mim assim. Sempre quis ser mãe, eu sempre quis amamentar" (Mãe 4).

"Eu acho que a interação com a criança, a criança sente mais próxima da gente, no entanto que, às vezes, eu pego ela no colo e ela fica procurando o peito entendeu porque eu acho que tem um vínculo maior" (Mãe 7).

Os itens lexicais "bom" e "gente" e suas conexões também reforçam as qualidades do leite materno em relação aos benefícios para mãe. São eles, ajudar a perder peso e retornar o tamanho do útero mais rapidamente. Além disso, o item lexical "consciência" indica que o conhecimento e a sensibilização da mãe quanto à importância da prática da amamentação exclusiva podem significar um aspecto motivador.

"Ajuda é que a gente perde o peso mais rápido, tanto é que eu estou bem mais magra do que antes de eu engravidar" (Mãe 5).

"Então a té bom para o útero voltar ao normal é essencial que você dê só o leite do peito, a partir do momento que você der outras coisas, além do desenvolvimento dele ser um pouco menor, para gente também, para o corpo da mulher, para o útero é pior. Não volta na velocidade que seria. (...) fui orientada como eu fiz cesárea, pro útero voltar ao normal, quanto mais peito dar, e essa questão de seis meses..." (Mãe 16).

"...Acho que propaganda falam sobre leite materno, pra gente sobre dar de mamar, eu acho assim elas que tinham que tomar consciência né, muitas mães têm que tomar consciência né da responsabilidade que é, o que é dar de mamar e tudo..." (Mãe 7).

\section{Discussão}

A análise das árvores de similitude revelou diferenças importantes nas suas estruturas. Referente às vivências negativas da amamentação exclusiva, a árvore de similitude apresentou configuração mais ramificada, evidenciando uma teia de inter-relações mais ampla comparada à configuração da árvore de similitude das vivências positivas.

Para o grupo estudado, realizar a amamentação exclusiva quer dizer que a subsistência da criança dependerá unicamente do peito da mãe, o que implica ter que atender a demanda constante da criança. Isso gera o sentido de obrigação, que se relaciona à impossibilidade de distanciar-se da criança. Dessa forma, as mulheres sentem-se tolhidas na realização de seus desejos, devido à rotina incessante de amamentar seu filho. O cansaço gerado pela demanda advinda da prática da amamentação é apon- 
tado como um dos motivos para o desmame precoce ${ }^{11}$. As mães precisam se adaptar à necessidade do filho de receber o leite que ela produz, e esse fato acarreta desajustes em suas vidas 12 . Embora priorizem e se acostumem com a amamentação, essa prática representa, para as mulheres, uma sobrecarga, gerando conflitos internos e relacionais 12 .

$\mathrm{Na}$ impossibilidade de distanciar-se da criança, a mulher se vê obrigada a permanecer sempre disponível para alimentá-la quando houver demonstração de fome e garantir a sua nutrição. Esse elo permanente, por vezes, pode ser visto como desestimulante, já que a mulher percebe essa condição como uma privação de sua liberdade. No mundo atual, a mulher ampliou seu papel na sociedade, e a concepção de maternidade vem tomando novo significado com as dificuldades da mãe em conciliar $\mathrm{o}$ atendimento às demandas do filho e aos seus próprios interesses 13 . Essa condição das mulheres exige que elas recebam apoio familiar, ou de outros, para que possam vivenciar a amamentação de forma saudável 13 .

A mulher tem dificuldade para adaptar-se a essa prática, por confrontar-se com uma rotina que não é a esperada ou que ela não foi preparada para enfrentar, e, com isso, sente-se esgotada já que essa tarefa demanda tempo disponível. O despreparo da nutriz constitui um aspecto importante a ser considerado na promoção da amamentação. Fujimori et al. 14, ao investigarem os aspectos relacionados ao estabelecimento da amamentação exclusiva, destacam que manter essa prática no dia a dia da mulher se configura em uma experiência complexa e de enfrentamento. Por isso, orientações sobre soluções práticas para as questões do dia a dia da mulher-mãe favorecem a adaptação à intensa demanda da criança, percebida como um processo longo e trabalhoso, que vai além de fornecer alimentação ao filho 14 .

A dor ao amamentar foi referida como uma vivência negativa, já que o grupo considerou que a nutriz precisa resignar-se com a dor para garantir a nutrição do filho. Os transtornos da mama e as dificuldades com o manejo da amamentação, causas apontadas para a dor, são desafios comuns que influenciam no estabelecimento do aleitamento materno 14,15 .

As intercorrências foram relatadas como fenômeno próprio da lactação, em que a mulher já espera vivenciá-las e suportá-las. De acordo com Junges et al. 16, mesmo que as mães considerem essas situações como obstáculo para a amamentação e que tenham seu estado emocional comprometido, buscam superar essas condições por acreditarem que é um evento natural e instintivo. Pesquisa sobre os conflitos da maternidade apontou que as mães priorizam as necessidades do filho mesmo diante de situações de desconforto, seguindo a lógica de que a superação das dificuldades da amamentação as qualifica como boa mãe 12 .

A percepção da mulher sobre a quantidade de leite produzida pode determinar o sucesso da amamentação. As mulheres relacionavam o choro da criança com a baixa produção de leite e, consequentemente, a não saciedade da fome da criança. A mulher interpreta o choro da criança como expressão de fome devido à sua baixa produção de leite, o que nem sempre pode ser verdadeiro 17 . Valores culturais repassados pelos familiares (principalmente os avós) e as vivências e os relatos de outras pessoas (vizinhos, amigos) sobre a quantidade ou as características do leite materno podem levar a mãe a acreditar que não é capaz de produzir leite de maneira satisfatória 16.

As mulheres, ao relatarem as vivências positivas da amamentação exclusiva, colocavam, em evidência, a criança e o valor do leite para a promoção da sua saúde. Também, expressavam como fator motivador o reconhecimento pela mãe de que ela é capaz de oferecer o melhor alimento para o filho. Estudos têm mostrado que o benefício do leite materno para saúde do filho é o motivo que mais influencia a mãe na decisão de amamentar 18,19. Pode-se inferir que a motivação para amamentar está intimamente ligada aos valores biológicos do leite que a induz a imputar responsabilidade a si pela oferta desse alimento que garante saúde ao filho 4,20. Deve-se considerar, no entanto, a influência das informações provenientes dos profissionais de saúde e meios de comunicação que valorizam os benefícios biológicos do leite materno para saúde e, consequentemente, podem levar as mulheres a repetirem esse discurso 20,21 .

As mães também evocaram o vínculo que se estabelece com seu filho pelo contato durante as mamadas. Dentro dessa abordagem psicoafetiva, as trocas entre mãe e filho são percebidas como condições que ressignificam a prática da amamentação exclusiva como um processo de profunda interação com a criança, uma condição que fortalece a autoconfiança e traz satisfação à mulher. Esse ato faz aflorar sensações prazerosas de afetividade, e as mães que amamentam parecem ser mais responsivas aos sinais do filho durante os processos de interação no início da vida 7,22. 
Os benefícios econômicos e a percepção de praticidade da amamentação também foram reconhecidos pelas mães. Segundo Frota et al. 19, os benefícios relacionados ao fator econômico podem representar importantes condicionantes para a manutenção da amamentação exclusiva, pois é valorizado pelas mães, principalmente para as que vivem em situação econômica desfavorável.

Embora a mulher seja a protagonista no processo da amamentação, suas decisões são fortemente influenciadas pelas concepções do companheiro. Assim, uma limitação do estudo foi não enfocar também a perspectiva do companheiro em relação à amamentação exclusiva.

\section{Conclusão}

Para o grupo estudado, as principais vivências negativas na amamentação exclusiva foram a demanda constante da criança pelo peito, a impossibilidade de distanciar-se da criança, a dor ao amamentar e a insegurança quanto à capacidade de produzir leite suficiente. Por outro lado, as principais vivências positivas foram os benefícios biológicos do leite materno, o vínculo mãe-filho, a praticidade e o menor custo. O estudo possibilitou a apreensão das dimensões positivas e negativas ligadas à amamentação exclusiva e sugere a importância da assistência profissional à mulher na fase inicial da amamentação e do apoio da rede social para amenizar a sensação de sobrecarga da mulher.

\section{Colaboradores}

G. P. Rocha participou na concepção e desenho do estudo, coleta de dados, análise e interpretação dos dados e redação do artigo. M. C. F. Oliveira e G. Z. Longo participaram na coorientação do estudo e análise dos dados. L. B. B. Ávila participou na coorientação, análise e interpretação dos dados. R. M. M. Cotta participou na coorientação do estudo e revisão do texto. R. M. A. Araújo participou na concepção e desenho do estudo, coleta de dados, análise e interpretação dos dados, redação do artigo e revisão crítica em todas as etapas do estudo.

\section{Agradecimentos}

Os autores agradecem à Coordenação de Aperfeiçoamento de Pessoal de Nível Superior (Capes), à Universidade Federal de Viçosa (UFV) e às participantes do estudo que tornaram possível a realização desta pesquisa.

\section{Referências}

1. Victora CG, Bahl R, Barros AJD, França GVA, Horton S, Krasevec J, et al. Breastfeeding in the 21st century: epidemiology, mechanisms, and lifelong effect. Lancet 2016; 387:475-90.

2. Kramer MS, Kakuma R. Optimal duration of exclusive breastfeeding. Cochrane Database Syst Rev 2012; (8):1-42.

3. Venancio SI, Escuder MML, Saldiva SRDM, Giugliani ERJ. A prática do aleitamento materno nas capitais brasileiras e no Distrito Federal: situação atual e avanços. J Pediatr (Rio J.) 2010; 86:317-24.

4. Almeida JAG, Novak FR. Amamentação: um híbrido cultura-natureza. J Pediatr (Rio J.) 2004; 80:119-25.

5. Boccolini CS, Carvalho ML, Oliveira MIC. Fatores associados ao aleitamento materno exclusivo nos primeiros seis meses de vida no Brasil: revisão sistemática. Rev Saúde Pública 2015; 49:91.

6. Araújo RMA, Almeida JAG. Aleitamento materno: o desafio de compreender a vivência. Rev Nutr 2007; 20:431-8.

7. Polido CG, Mello DF, Parada CMGL, Carvalhaes MAB, Tonete VLP. Vivências maternas associadas ao aleitamento materno exclusivo mais duradouro: um estudo etnográfico. Acta Paul Enferm 2011; 24:624-30.

8. Silva IA. Amamentar: uma questão de assumir riscos ou garantir benefícios. São Paulo: Robe; 1997. 
9. Fontanella BJB, Luchesi BM, Saidel MGB, Ricas J, Turato ER, Melo DG. Amostragem em pesquisas qualitativas: proposta de procedimentos para constatar saturação teórica. Cad Saúde Pública 2011; 27:388-94.

10. Organización Mundial de la Salud. Indicadores para evaluar las prácticas de alimentación del lactante y del nino pequeño: conclusiones de la reunión de consenso llevada a cabo del 6 al 8 de noviembre de 2007 en Washington, DC, EE.UU. Geneva: Organización Mundial de la Salud; 2009.

11. Rodrigues BM, Pelloso SM, França LCR, Ichisato SMT, Higarashi IH. Aleitamento materno e desmame: um olhar sobre as vivências de mães enfermeiras. Rev Rene 2014; 5:832-41.

12. Nakano AMS. As vivências da amamentação para um grupo de mulheres: nos limites de ser "o corpo para o filho" e de ser "o corpo para si". Cad Saúde Pública 2003; 19 Suppl 2:355-66.

13. Cunha ACB, Santos CS, Gonçalves RM. Concepções sobre maternidade, parto e amamentação em grupo de gestantes. Arq Bras Psicol 2012; 64:139-55.

14. Fujimori E, Nakamura E, Gomes MM, Jesus LA, Rezende MA. Issues involved in establishing and maintaining exclusive breastfeeding, from the perspective of women attended at a primary healthcare unit. Interface Comun Saúde Educ 2010; 14:315-27.

15. Castelli CTR, Maahs MAP, Almeida ST. Identificação das dúvidas e dificuldades de gestantes e puérperas em relação ao aleitamento materno. Rev CEFAC 2014; 16:1178-96.
16. Junges CF, Ressel LB, Budó MLD, Padoin SMM, Hoffmann IC, Sehnem GD. Percepções de puérperas quanto aos fatores que influenciam o aleitamento materno. Rev Gaúcha Enferm (On-line) 2010; 31:343-50.

17. Rocci E, Fernandes RAQ. Dificuldades no aleitamento materno e influência no desmame precoce. Rev Bras Enferm 2014; 67:22-7.

18. Primo CC, Nunes BOM, Lima EFAL, Leite FMC, Pontes MB, Brandão MAG. Quais os fatores que influenciam as mulheres na decisão de amamentar? Invest Educ Enferm 2016; 34:198-210.

19. Frota MA, Casimiro CF, Bastos PO, Sousa Filho OA, Martins MC, Gondim APS. Mothers' knowledge concerning breastfeeding and complementation food: an exploratory study. Online Braz J Nurs 2013; 12:120-34.

20. Machado MMT, Bosi MLM. Compreendendo a prática do aleitamento exclusivo: um estudo junto a lactantes usuárias da rede de serviços em Fortaleza, Ceará, Brasil. Rev Bras Saúde Matern Infant 2008; 8:187-96.

21. Demétrio F, Silva MCM, Chaves-dos-Santos SM, Assis AMO. Meanings attributed to breast feeding in the first two years of life: a study with woman from two municipalities in the Recôncavo Baiano region of Bahia, Brasil. Rev Nutr 2013; 26:5-16.

22. D'Artibale EF, Bercini LO. O contato e a amamentação precoces: significados e vivências. Texto Contexto Enferm 2014; 23:109-17. 


\section{Abstract}

The study aimed to explore the positive and negative experiences of mothers with exclusive breastfeeding. A descriptive, qualitative study enrolled 18 breastfeeding mothers of infants $(\leq 1$ year) recruited in the Municipal Immunization Service in Viçosa, Minas Gerais State, Brazil. Data were obtained from taped, transcribed interviews and submitted to content analysis to verify the thematic units related to positive and negative experiences, after which two texts were drafted, one for each situation. These texts were submitted to similarity analysis with the IRAMUTEQ software, generating two similarity trees. Interpretation of the similarity trees used concordance lines produced by the AntConc software. The principal negative breastfeeding experiences were the infant's constant demand for the breast, the impossibility of leaving the infant alone, painful breasts, and insecurity concerning the capacity to produce enough milk. The main positive experiences were the biological benefits of breastmilk, practicality, and lower cost. The study allowed grasping the positive and negative dimensions of exclusive breastfeeding and suggests the importance of professional assistance for the woman in the initial phase of breastfeeding, plus social network support to mitigate the woman's overburdened feeling.

Breast Feeding; Weaning; Infant; Mothers

\section{Resumen}

El objetivo del estudio fue explorar, entre mujeres embarazadas, las vivencias positivas y negativas en relación con la práctica de la lactancia exclusiva. Se realizó un estudio descriptivo, cualitativo, involucrando a 18 mujeres embarazadas, con hijos de hasta un año de edad, captadas en el Servicio de Inmunización del municipio de Viçosa, Minas Gerais, Brasil. Los datos se obtuvieron mediante entrevistas grabadas y transcritas. El corpus se sometió al análisis de contenido para la investigación de las unidades temáticas, relacionadas con las vivencias positivas y negativas, y en seguida se construyeron dos textos correspondientes a cada situación. Estos textos se sometieron a un análisis de similitud con la ayuda del software IRAMUTEQ, generando dos árboles de similitud. La interpretación de los árboles de similitud se realizó a partir de las líneas de concordancia producidas por el software AntConc. Las principales vivencias negativas en la lactancia exclusiva fueron la demanda constante del bebé de pecho, la imposibilidad de distanciarse del bebé, el dolor al amamantar y la inseguridad en cuanto a la capacidad de producir leche suficiente. Las principales vivencias positivas fueron los beneficios biológicos de la leche materna, el vínculo madre-hijo, la practicidad y el menor coste. El estudio posibilitó la aprehensión de las dimensiones positivas y negativas vinculadas a la lactancia exclusiva y sugiere la importancia de la asistencia profesional a las mujeres en la fase inicial de la lactancia y del apoyo de la red social para amenizar la sensación de sobrecarga de la mujer.

Lactancia Materna; Destete; Lactante; Madres

Recebido em 23/Mar/2017

Versão final reapresentada em 28/Nov/2017

Aprovado em 12/Jan/2018 